\title{
China across the "Middle Income Trap" Dynamic Mechanism and Path Selection
}

\author{
Jie Fan \\ Department of Political Theory Teaching, Nanyang Institute of Technology, Nanyang, China \\ fanjie12@163.com
}

Keywords: Middle income trap; Mechanical machine; Path selection; Industrial upgrading

\begin{abstract}
Demographic dividend play advantage, improve market supply factors, optimize the industrial structure, promote independent innovation is the main driving force of China's economic growth in the current long-term, to maintain growth momentum and success across the "Middle Income Trap", Feasible path include: emphasis on economic restructuring and the development of new industries consumption upgrading investment structure. The former relies on effective docking innovative spirit and ability to integrate large-scale industrial enterprises of small and medium enterprises; the latter long-term dependence on income distribution accounted for the proportion of the national economy steadily. Given that consumption declined upgrade depends on disposable income and savings rate of improvement can be expected, Consumption transformation is a long-term trend of China's economic development, industrial policy and the restructuring of the investment is countermeasures current economic problems.
\end{abstract}

\section{Introduction}

The World Bank in 2006 in the East Asia Economic Development Report Time put forward the concept of the Middle Income Trap, It pointed out that the level of economic development, although some developing countries into the ranks of middle-income, but find it difficult to enter the ranks of high-income, per capita income is difficult to over $\$ 10,000$ limit, economic growth remained at the middle-income range, a long period of slow growth or even stagnation [1-4]. China is undergoing reform and opening up; per capita GDP has increased from the beginning of reform in 1978 \$ 154 to $\$ 8,000$ in 2015 . From international experience and research results, the per capita GDP reached $\$ 3,000$, economic growth in high-growth countries will be significantly decreased, some countries quickly slipped from a high growth phase to a low or even negative growth stage, economy has not yet caught on across the high-income countries continued to pause, fall into the "middle income trap" in some countries rely on the development and transformation and structural adjustment, maintain a longer period of fast growth, successfully into the ranks of developed countries [5-7]. This shows, to achieve steady growth after the fall, and to extend the period of the medium-speed growth path, success across the middle-income trap \# $\$$ is the present stage must answer a major issue.

\section{First, the Chinese across the "Middle Income Trap" Dynamic Mechanism}

From the current point of view of economic growth, China over-reliance on long-term economic growth model of investment has played a positive role in solving the "shortage economy" [8]. In the long run, "Over-investment" has been overdrawn future demand; increase the share of income distribution and government enterprises, which accounted for the decline in income, resulting in a lack of purchasing power to support residents of excess capacity. Lower the threshold to invest a lot of resources, can rapidly improve the GDP of industry. Part of the reason behind this is due to the GDP and local government tax revenue blindly, will inevitably result in around the convergence of industrial structure, Investment yield decreased widespread phenomenon. This stage of business will inevitably have high capacity expansion requirements [9]. Overall, large-scale investment in such infrastructure improvements, to expand the industrial scale, increased ability to support 
economic growth into the path of convergence. Convergence of economic growth also contributed to the convergence of industrial structure, the formation of capital accumulation and economies of scale, the formation of a certain competitive advantage! By the late investment-driven model, Excess demand for investment goods and raw materials caused a rise in factor costs, but overcapacity will lead to decreased prices of manufactured goods, the overall slowdown the accumulation of wealth, investment yields fell [10-11]. Measure the effectiveness of large-scale investment should be at least four criteria: First, there is abundant labor to meet the needs of economic growth and industrial restructuring; the second is to meet the growing market demand; third, optimize the structure, reducing consumption to achieve structural upgrading; fourth, to promote independent innovation, promote technological progress. This shows, how to improve the above four points is whether China will cross the "middle income trap" active force.

Play a Demographic Dividend Advantage. Demographic dependency ratio data by simple fitting can know, a gradual decline in child dependency ratio and gradually rising elderly dependency ratio change ultimately cancel each other out, the total dependency ratio is expected to reach the theoretical minimum value of $36 \%$. Chinese NPC Standing Committee voted through December 27, 2015 the Population and Family Planning Law amendment policy: adhere to the basic state policy of family planning, improve the population development strategy, the full implementation of a couple to have two children policy and actively efforts to respond to population aging action, scheduled to face two children from January 1, 2016 formally implemented. In the present established industrial structure, China may be a "shortage of young labor force $\mathrm{f}$ " and "middle-aged labor surplus" long-term coexistence. Demographic factors is an important factor in economic growth, as the demographic dividend period approaching the end of the window, and actively respond to the challenges of population growth and structural change has been brought about is an unavoidable problem. Experts predict imminent demographic dividend inflection point will lead to transformation of China's economic growth mode, mainly reflected in the following five areas: First, potential economic growth will moderate level of the central or down; second, the distribution of income or increased remuneration will drive the rise of the consumer; third, the production factor input ratio change or will increase labor productivity; fourth, demographic changes or will bring about changes in the industrial structure; fifth, or demographic changes will lead to changes in consumption structure and expenditure structure.

Improving Market Supply Factors. From the current situation, developed regions facing scarcity of land resources, rising energy prices, faced with the internalization of environmental costs, RMB appreciation, water resources, mineral resources, taxes, fees, price increases, rising labor costs and other multiple pressures, which are directed transformation of economic growth strong signal. Microscopic point of view, the enterprise is to promote the upgrading of industrial structure of the body. The introduction of new technology can enhance the value-added industries through less consumption of resources; promote economic growth in the resource facing scarcity conditions. In the following domestic investment-driven economic growth in the background, you can take advantage of long-term off ten industrial investment growth, and promote the upgrading of industrial structure.

Optimize the Industrial Structure, Upgrading the Industrial Structure. Find the country from the situation; the economic entities of large enterprises have long stays in manufacturing. Shift in the needs of the community, under the excess manufacturing capacity universal case for the fields of national economy has a significant impact on trade has shifted to the service sector and in some emerging industrial systems such as financial systems, social security systems. The large number of state-owned capital is still stuck in the traditional manufacturing industry already cannot reflect the "lifeline of the national economy," the control, will form a crowding out of non-public capital. This wrong with state-owned capital should be attributed to the market is not enough, lack of liquidity factors, low capacity efficiency. Long supported China's rapid economic growth into a leading industry overcapacity status, expansion of space disappears. New industries may create new growth point of China's industry, which is also a useful attempt to change the state-owned capital operation mode. On the one hand, this means that China's state-owned enterprises can take advantage of its 
strong financial strength, strategic vision and technology ahead of the layout has a promising area to achieve industrial upgrading and recycling capacity; on the other hand, consider the state capital budget, the establishment of industry funds by operation of the market into new industries.

To Promote Independent Innovation, Promote Technological Progress. The leading role of SMEs in ten relatively primitive technology innovation and application, large enterprises strong industrial capacity and complexity of technology integration cannot be replaced. Through market-oriented operation of large enterprises can integrate the fields of investment, supply chain, market development, the core competitiveness performance for technology integration and industrialization. These inherently require large companies can capture information and market value of the new technology, and projected onto the development of new products. Enterprise in the original high-tech innovation and strategic capital investments have generally selected a specific industry background, long-term return expectations and industrial applications attempt to research projects. Such studies can be inherently growth-promoting application of technology and technological upgrading, and may even be extended to a huge new industry.

\section{China across the "Middle Incomes Trap" Choice: Consumer Restructuring and Industrial Upgrading}

Throughout the country success across the middle-income trap, the basic experience is changing the industrial structure, investment and exports to consumption in transition, innovative use of technology to improve labor productivity, and the reconstruction of social protection mechanisms adapted to industrial production and so on. Based on this, we will invest in transition mode of consumption economic restructuring and industrial structure of China's economy is considered the Middle Income Trap across the two choices.

Long- term Changes in Consumption Driven by the Rise in the Economic Growth Model. Rising consumption of long-term dependence on income distribution in the proportion of labor Elements, which will be China's economic model transformation and upgrading of the long-term trend. Chinese consumption share has been low due to the soil-financing income share of GDP of a downward trend in income method of accounting GDP of Earth capital income share in 2003 from $49.6 \%$ in 2009 , down $38 \%$. However, in rural areas can transfer the number of the young labor force decreased from 100 million around 2005 to 2010, 30 million, is expected to decline further. In recent years, once after the Spring Festival with soil shortage phenomenon also indicates that the rise in labor costs, average soil resources, especially the rapid increase in low-end labor-owned land and labor skills soil. Labor supply inflection point, suggesting that the composition of China's economic structure must change dumb. Consumption share trend of increase depends on the lifting of disposable income, while the increase in disposable income is the Lewis turning point marked. At this time will show a labor shortage, soil resources appear to rise pushing up the cost of inflation, while an economy to fall into "stagflation" dilemma being. This is obviously also possible Chinese demographic dividend will disappear after the predicament faced. Since 2009, after the next four trillion investment stimulus policy, China's infrastructure construction has been a comprehensive progress, transportation, electric power set up with the rapid development of telecommunications networks in order to stimulate investment, create jobs, increase foreign exchange basis. But from the point of view constraints, slow growth in labor income, and income distribution gap is too large a decline in the marginal propensity to consume, the asset price bubble makes the process of urbanization has been blocked, it is difficult to further improve labor productivity, which in turn makes consumption enhance the role of the economy in the short term is still not too obvious. Consumer environment is difficult to improve in the short term, incremental consumption is still largely dependent on the derived demand passively ten investment. 1 January 2016, after China's family planning policy adjustment, comprehensive "open two-child" policy after the second child for the purposes of release,, positive Chinese economy mainly for long-term aging of the buffer; the economy trends in short-term impact is relatively limited. Even so, the full liberalization of the second child is the equivalent of China's aging found a theoretical equilibrium solution (specific effects to be verified afterwards), the positive impact of Chinese assets on expectations cannot be 
ignored. Moreover, some directly related industries will benefit from the baby boom. Press into a 16-year-old historical city of 200,000 rural average cost of raising a rough estimate, the second child baby boomers inherent consumption bonus of about 1200-1600 billion annually. In the short term, the arrival of a second child baby boomers will boost the development of related food products, toys, maternal and child health care, children's clothing, household cars, education and training sectors; the medium term, the arrival of a second child baby boomers will change the country's population ages China structure, slowing the aging rate, real estate and other industries will be part of the benefit.

Investment Structure Adjustment and Optimization of Industrial Structure. At present China's economic growth model presented convergence formula manufacturing growth and endogenous growth model modern economic state of coexistence, and the driving force of future economic growth lies in a smooth transition between two economic growth pattern. China as a developing economy can absorb and utilize the advantage of experience and technology developed economies, economic growth in the traditional style of convergence on the basis of established infrastructure and the development model of modern economy needs. In the soil of industrialization and urbanization process of deepening the same time, the modern model of economic growth requires the development of more high-tech industries, high-end equipment manufacturing industry to occupy the high-end supply chain and producer services to stimulate growth, create domestic demand, to solve the employment problem. Obviously, this is the "structural adjustment" policies determined by the focal point and the direction of development. Investment structure and industrial structure change should include not only macro-scaled investment, consumption and between imports and exports, should also include regional economic structural imbalances mesa level, the development and upgrading of traditional industries to enhance the creative industries, and even include microscopic cultivating enterprise level productivity improvement and innovation ability. Upgrade traditional industries requires us to inefficiency, low value-added industrial integration and reengineering; foster innovation and industry leading industry requirements to guide investment, elimination of monopoly industries, the implementation of opening up and so on.

Elimination of excess production capacity, reduce resource inputs, which reduce carbon emissions guiding ideology. Environment-friendly, resource-saving product line and soil process flow can improve total factor productivity, while a reduction of environmental and resource costs most supported the transformation of economic policy; regional Second, investment patterns between metastasis. Midwest inadequate capital formation, investment in fixed assets there is considerable space. To promote the effective integration of the less developed regions resources, labor and capital, it is to change the regional economic imbalances main focus; Third, investment in new industries. New industry development plan is to guide the transformation of China's investment important development ideas. These are industries with strategic development status, can form a first-mover dominance, with the wind in order to invest in the field of high value-added. November 2015, the CPC Central Committee in financial and economic work meeting, Xi Jinping's speech that "supply-side reform" that is market-oriented, market supply to supply the required standard of reform, to level the market access threshold, the real equal national treatment, to reduce the degree of monopoly, relax administrative control, reduce financing costs, tax breaks to help people reduce the supply of land, labor, technology, capital, management and other production factors limit reform.

\section{Summary}

In summary, based on across the "middle income trap" dynamic analysis of current across the "middle income trap" upgrade path options include emphasis on the investment structure of consumption of economic restructuring and development of new industries. Since consumer promotion depend ten residents' disposable income decline upgrading and savings rates, so consumption transformation is a long-term trend of China's economic development; investment and industrial restructuring policy is a policy to deal with the current economic problems. 


\section{Acknowledgement}

The author is grateful to the support of Henan Province Soft Science Research Plan Projects (122400430153).

\section{References}

[1] Y. Li, M. Zhou. Economic Theory and Economy, (2012) No.9, p.32.

[2] G. Fan, X.J. Zhang. Management World, (2013) No.1, p.42.

[3] W.J. Lu. Economist, (2012) No.5, p.32.

[4] Y.S. Ji, L.J. Guan. Journal of Jiangsu Administration Institute, (2012) No.5, p.32.

[5] Z. Chen. Oriental Outlook Weekly, (2012) No.43, p.13.

[6] J.L. Wu. New Economic Navigation, (2011) No.12, p.45.

[7] D.C. Fang. Macro-Economic Management, (2011) No.7, p.26.

[8] S.X. Jiang. World knowledge, (2011) No.7, p.39.

[9] B.W. Zheng. Foreign Theoretical Trends, (2011) No.7, p.52.

[10]B.W. Zheng. China Comment, (2011) No.5, p.18.

[11]F.H. Liu. Southern Window, (2011) No.6, p.47. 